\title{
PREÂMBULOS À PRESERVAÇÃO DIGITAL NA REDE DE BIBLIOTECAS DA FIOCRUZ: ESTUDO EXPLORATÓRIO SOBRE A CONSTRUÇÃO DE AÇÕES INSTITUCIONAIS VOLTADAS À SALVAGUARDA DE SUAS COLEÇÕES
}

\author{
INTRODUCCIÓN A LA PRESERVACIÓN DIGITAL \\ EN LA RED DE BIBLIOTECAS DE FIOCRUZ: UN \\ ESTUDIO EXPLORATORIO ACERCA DE LA \\ CONSTRUCCIÓN DE ACCIONES \\ INSTITUCIONALES
}

\begin{abstract}
Manoel Silva Barata - cinfbarata@gmail.com Mestre em Biblioteconomia pelo PPGB/UNIRIO. Casa de Oswaldo Cruz. Fundação Oswaldo Cruz

Gustavo Silva Saldanha - gustavosilvasaldanha@gmail.com Doutor em Ciência da Informação pelo convênio IBICT/UFRJ.

Professor do PPGCI - IBICT-UFRJ e do PPGB-UNIRIO
\end{abstract}

\section{RESUMO}

Introdução: Apresenta uma contribuição teórico-empírica ao domínio da preservação nos estudos biblioteconômicos no que tange às informações técnico-científicas armazenadas em suportes digitais.

Objetivo: Compreender a ação do bibliotecário na preservação da memória técnico-científica digital contemporânea sob o ponto de vista biblioteconômico, a partir de análise sobre a Rede de Bibliotecas da Fiocruz.

Metodologia: Análise teórica: através de revisão da literatura sobre a razão filosófica para "preservar" e o papel "discursivo" da preservação no contexto da Biblioteconomia; análise empírica: através da aplicação de questionários com entrevistas aos bibliotecários atuantes da Rede de Bibliotecas da Fiocruz, levantamento secundário, a partir de questionários autoaplicados no quadro de bibliotecários participantes em um fórum específico de preservação na instituição.

Resultados: $O$ estudo permitiu obter resultados oriundos da reflexão teórica e empírica sobre a ação do bibliotecário em benefício da preservação digital, sob o ponto de vista biblioteconômico, no contexto da Rede de Bibliotecas da 
Manoel Silva Barata; Gustavo Silva Saldanha

Preâmbulos à preservação digital na rede de bibliotecas da Fiocruz: estudo exploratório sobre a construção de ações institucionais voltadas à salvaguarda de suas coleções

Fiocruz.

Conclusões: A preservação da memória técnico-científica digital, diferentemente da memória técnico-científica analógica, caracteriza-se por ser mais complexa quando tratamos da noção de durabilidade e da noção de confiabilidade, e demanda uma constante reavaliação interdisciplinar. Entendese que atualmente este tema pode ser investigado por diversas disciplinas acadêmicas, dentre elas está a Biblioteconomia.

Palavras-Chave: Preservação Digital. Bibliotecário. Teoria biblioteconômica. Fiocruz.

\section{INTRODUÇÃO}

Apoiados em Darnton (2010) e Rendón Rojas (2005), podemos inferir que a biblioteca, interpretada como instituição informativa, é uma das organizações estabelecidas historicamente como a responsável pela organização, armazenamento, preservação e disseminação da informação registrada em qualquer tipo de suporte. Tal organização vem, ao longo do tempo, apesar das inúmeras dificuldades e transformações sócio técnicas, vem cumprindo a sua árdua função social, principalmente pelo esforço dos bibliotecários. Estes acumulam hoje mais um desafio: o de garantir a perpetuação dos conhecimentos registrados em suportes digitais.

A UNESCO fundamenta a importância dos serviços de arquivos e bibliotecas para a disseminação e preservação desta herança cultural, alertando que

[...] para cumprir esses dois objetivos com sucesso, é necessário elaborar uma política de preservação a longo prazo com os objetivos de prevenir ou retardar a deterioração dos documentos e melhorar as condições de preservação de acervos ou, pelo menos, a salvaguarda do conteúdo através da criação de documentos substitutos - analógico ou digital. (UNESCO, 2005, p. 6, tradução nossa).

De acordo com o avanço da produção de informação técnicocientífica digital, as demandas pelas atividades em prol da preservação 
digital - e, consequentemente, pelos bibliotecários - tendem a crescer. Para que esta demanda se concretize em oportunidade para a área da Biblioteconomia, acredita-se que estes profissionais deverão atuar se adaptando aos diversos ambientes de trabalho existentes nas instituições, sejam estes híbridos ou altamente tecnológicos, sempre com o propósito final de contribuir com a prática baseada em processos que garantam uma preservação de longo prazo, através da participação nas atividades correntes, de curto prazo, assim como nas políticas de preservação para os acervos (estas, de médio prazo), independentemente do suporte em que estejam registradas as informações.

$\mathrm{Na}$ busca por esta compreensão, essa pesquisa teve início durante a prática profissional, mais especificamente no nosso setor de trabalho, a partir do momento em que paramos para refletir sobre 0 vertiginoso crescimento de migração dos suportes informacionais analógicos para os digitais, ao mesmo tempo em que a biblioteca parece se afastar da responsabilidade pela preservação destes novos suportes.

Os bibliotecários historicamente são os responsáveis diretos por suas coleções e, portanto, se o suporte informacional que compõe a coleção está em constante transformação, o bibliotecário tem a necessidade de encontrar meios de acompanhar esta mudança no intuito de compreender o que acontece em seu entorno, propor e contribuir com modelos, programas e ações que venham a proteger 0 patrimônio cultural e informacional digital, dialogando com a teoria biblioteconômica que justifica sua atuação.

Em levantamento bibliográfico realizado constatou-se que há pouca publicação de caráter histórico-epistemológico sobre a preservação digital. Pressupôs-se ainda, para efeito desta pesquisa, que os processos profissionais no ambiente das bibliotecas careciam de um maior embasamento teórico, e que esse embasamento viria contribuir com práticas críticas e efetivas no contexto da preservação da memória 
técnico-científica, resultando em uma atuação mais ativa no ciclo da informação digital, desde o nascimento e curadoria, até o gerenciamento de seu acesso aos usuários interessados.

Tendo em vista a emergência da produção de documentos eletrônicos e a relevância sócio-política dos documentos na atualidade em instituições dedicadas à ciência e tecnologia, indagou-se: como o bibliotecário, enquanto profissional e teórico inserido diretamente no contexto de produção, circulação e uso destes documentos, intervém técnica e politicamente nas ações institucionais de preservação da memória técnico-científica digital?

Para identificar as possíveis respostas para essa questão, o objetivo principal dessa pesquisa foi compreender a ação do bibliotecário na preservação da memória técnico-científica digital contemporânea sob o ponto de vista biblioteconômico, a partir de análise sobre a Rede de Bibliotecas da Fiocruz.

\section{SOBRE A PRESERVAÇÃO NA FIOCRUZ}

A preservação dos acervos existentes hoje na Fundação Oswaldo Cruz entendida como prática profissional é uma preocupação histórica anterior ao seu surgimento oficial, em maio de 1970. Dentre as diversas contribuições de profissionais com a preservação, recordamos ao prefácio do livro de Monsenhor Nabuco, onde vemos uma efetiva contribuição sobre preservação do médico epidemiologista Arthur Neiva, que "trabalhou [...] no Instituto Soroterápico Federal, posteriormente denominado Instituto Oswaldo Cruz (IOC)." (BASE ARCH, 2014).

$\mathrm{Na}$ primeira edição da publicação 'Em defesa do livro', de Monsenhor Nabuco, publicado em 1942, Arthur Neiva demonstra sua preocupação com a propagação de pragas nos acervos bibliográficos existentes na Biblioteca de Manguinhos, 
[...] ilustre Monsenhor Nabuco, na minha desvaliosa opinião, acredita demasiado na ação do frio para a debelação dos bibliófagos. Tal fato somente poderá retardar a evolução daqueles inimigos, mas não destruílos. Para se obter, entre nós, uma média da temperatura que não permita o desenvolvimento dos bibliófagos, havia necessidade de instalações ainda muito onerosas. Penso que uma temperatura média elevada e constante atue mais que o frio; pelo menos é o que se tem observado na Biblioteca de Manguinhos. (NEIVA, 1942 apud NABUCO, 1959, p. 16).

Neiva (1942 apud NABUCO, 1959) aponta para questões relacionadas à conservação preventiva do acervo impresso em papel vegetal quando fala nos predadores biológicos; do controle da temperatura e do ambiente; e da necessidade de investimento em estruturas ideais de preservação 'ainda muito onerosas' para a Instituição.

Para além dessas preocupações, Neiva (1942 apud NABUCO, 1959) nos demonstra claramente o valor que deve ser dado à preservação da memória contida nos livros e a importância em preserválos para as futuras gerações. O alerta e indica aos seus contemporâneos que perderam seus acervos por alguma tragédia, como fogo ou devastação por pragas, a leitura do livro do Monsenhor Nabuco. Neiva diz que, em seu passado

[...] toda casa da melhor classe possuía uma biblioteca, $\mathrm{e}$ isso para mim constitui uma das mais gratas recordações da minha meninice, encontrarão, no utilíssimo livro do Monsenhor Nabuco, os ensinamentos indispensáveis para melhor conservá-los e preservá-los dos seus principais inimigos. (NEIVA, 1942 apud NABUCO, 1959, p. 19).

Em 1982, um grupo de notáveis cientistas brasileiros demonstrou preocupação com a prática da história das ciências no Brasil e consequentemente com a preservação da memória técnico-científica. Como materialização destas preocupações, foi concebido um 
documento muito significativo. "A Carta dirigida ao presidente do $\mathrm{CNPq}$ era representativa da comunidade científica da época, sua lista de assinaturas sendo encabeçada por Carlos Chagas Filho, cientista de alto reconhecimento internacional." (DOMINGUES, 2012, p. 640).

Os frutos desse movimento encabeçado pelo cientista Carlos Chagas Filho, começaram a surgir de forma concreta, pois,

[...] pouco após a reunião realizada no Observatório Nacional, surgiriam as instituições especializadas na pesquisa em história das ciências e na preservação da memória científica do Brasil [...] Em 1985 foram criadas, na Fundação Oswaldo Cruz (Fiocruz), a Casa de Oswaldo Cruz (COC) e no CNPq, hoje Instituto do Ministério de Ciência e Tecnologia, o Museu de Astronomia e Ciências Afins (Mast). (DOMINGUES, 2012, p. 640).

Carlos Chagas Filho, aliado ao seu grupo de cientistas, para além das obras concretas realizadas, deixou também um legado político fundamental, ou seja, uma contribuição epistemológica sobre a importância da preservação da memória e do patrimônio científico no Brasil.

Inserida no contexto desta instituição atenta à preservação da ciência a partir dos seus registros, essa pesquisa entende como preservação da memória o sentido estrito do termo, ou seja, a memória tem a "[...] propriedade de conservar certas informações, remete-nos em primeiro lugar a um conjunto de funções psíquicas, graças às quais o homem pode atualizar impressões ou informações passadas, ou que ele representa como passadas." (LE GOFF, 1996, p. 423). Reconhece-se também, como aliado à noção indicada, o conceito de patrimônio, pelo aspecto mais concreto vinculado à memória e à preservação, tendo em vista que "[...] o conceito de patrimônio é adequado as ideias de herança, tradição, conhecimento, experiência, legado e vivência, entre outras expressões que denotam a ideia de transmissão natural da cultura, de uma geração à outra" (DODEBEI, 2008, p. 27). 
Manoel Silva Barata; Gustavo Silva Saldanha

Preâmbulos à preservação digital na rede de bibliotecas da Fiocruz: estudo exploratório sobre a construção de ações institucionais voltadas à salvaguarda de suas coleções

Para tanto, a UNESCO criou a "figura de Patrimônio Cultural da Humanidade" - aqui encontramos, juntas, "[...] nas mesmas expressões, as noções difusas de humanidade e de uma cultura universal, e a noção cada vez mais precisa de uma cidadania fundada em direitos diversificados, para legitimar a atividade de preservação." (FONSECA, 2009, p. 65). Percebe-se aqui o foco político internacional, orientando para o compartilhamento dos bens culturais de todos os países do mundo e a busca de um compromisso unívoco de preservação.

Desta maneira, a preservação do biblion contendo informações constitui uma angústia social de longa data para as unidades informativas institucionalizadas socialmente, pois,

[...] desde a invenção da escrita que existe uma manifesta preocupação pela preservação dos artefactos que resultam de processos intelectuais e criativos do ser humano. A preservação desses artefactos permite às gerações futuras compreender e contextualizar a história e a cultura dos seus povos. Os museus, as bibliotecas e os arquivos assumem neste contexto um papel determinante, responsabilizando-se pela preservação e longevidade desses artefactos. (FERREIRA, 2006, p.17).

O conceito de preservação, como um ato de preservar a memória de uma ou mais gerações para as futuras sob a observação crítica da contínua transformação da sociedade, resulta em compreender, delimitar e preservar o patrimônio informacional da humanidade, sem que seja necessário (re)começar do marco zero no transcorrer de um lapso histórico contínuo, para tanto, acentua-se sobremaneira a responsabilidade das instituições e dos profissionais inseridos no contexto da informação técnico-científica. 


\subsection{Políticas de Preservação na Fiocruz}

Por toda a sua história, a Fiocruz se mostrou preocupada com a preservação de seu patrimônio, porém mais recentemente vive um momento significativo em relação às suas políticas de preservação do patrimônio e da memória técnico-científica da área de saúde. Tais esforços vêm sendo reconhecidos e compartilhados institucionalmente, formulando estratégias e articulando ações conjuntas. Dentro deste cenário de gradativa mutação, temos como iniciativa mais contundente e pragmática o desenvolvimento de um projeto para abrigar suas diversas tipologias de acervo, o Complexo de Preservação e Difusão de Acervos Culturais e Científicos da Saúde - CPDACCS cujo

[...] objetivo é estabelecer a infraestrutura destinada à preservação do patrimônio científico e cultural, bem como à gestão da qualidade e do conhecimento na Fiocruz, tendo como eixos estruturantes de uma política institucional de preservação e gestão de seu acervo científico a conservação integrada, a conservação preventiva, o desenvolvimento e o emprego de estratégias sustentáveis, e a maior articulação entre a preservação patrimonial e as tecnologias da informação e comunicação. (PINHEIRO; SANTOS; COELHO, 2011, p. 1).

Trata-se de uma iniciativa ampla com o objetivo de preservar a memória técnico-científica com o uso das novas tecnologias e integração de diferentes tipologias informacionais, "[...] que abrange tanto os acervos que registram as atividades científicas, quanto os arquivos que são fontes de pesquisa para as ciências humanas, biológicas e sociais." (PINHEIRO; SANTOS; COELHO, 2011, p. 5). Além disso, tal projeto concebe a preservação como uma série de processos interligados que necessitam se desenvolver em sintonia, para que 0 produto final seja entregue à sociedade com qualidade. Esta preservação é subdividida em processos "[...] enquanto coleta, 
organização, sistematização, conservação, restauração, pesquisa e disseminação." (PINHEIRO; SANTOS; COELHO, 2011, p. 1).

Por sua vez, a Rede de Bibliotecas da Fiocruz vem buscando contribuir com uma melhor organização e compartilhamento dos serviços e produtos oferecidos pelas bibliotecas que a compõem, tendo elaborado em 2002 "[...] um documento para direcionar sua política de desenvolvimento de coleção, chamado de Política de Seleção." (SILVA, 2010 , p. 55). Além de constar em seu regimento, no principal documento normativo da Rede de Bibliotecas Fiocruz, indica-se o estímulo à cooperação, à padronização e à racionalização, integrando suas bibliotecas. Estabelece-se aqui o compromisso de

[...] potencializar e agilizar o intercâmbio e o uso de informações e expandir o seu acesso e disponibilidade, para atender às necessidades e demandas de informação da comunidade científica e tecnológica em saúde assim como a sociedade em geral. (FUNDAÇÃO OSWALDO CRUZ, 2008 apud SILVA, 2010, p. 56).

Além das diversas questões práticas e recomendações mencionadas anteriormente que impactam diretamente as bibliotecas e que contribuem com a preservação digital dos acervos culturais e técnico-científicos sobre a tutela da instituição, atualmente estão previstos o fortalecimento do ARCA, como repositório institucional, e o desenvolvimento de um sistema integrado de acervos, tanto para preservar como para disseminar a informação à sociedade de uma maneira geral.

O ARCA, "Repositório Institucional (RI) da Fiocruz, foi concebido com 0 intuito de disseminar e preservar a produção intelectual da Fundação." (FREYRE, 2013, p. 12). Atualmente este repositório é coordenado pelo Instituto de Comunicação e Informação Científica e Tecnológica em Saúde (ICICT) e possui no cerne de sua definição a preocupação com a preservação e o acesso à informação técnicocientífica. 
Manoel Silva Barata; Gustavo Silva Saldanha

Preâmbulos à preservação digital na rede de bibliotecas da Fiocruz: estudo exploratório sobre a construção de ações institucionais voltadas à salvaguarda de suas coleções

Para cumprir todas as responsabilidades que um repositório se propõe, o ARCA utiliza-se das novas tecnologias da informação, normas e padrões para entrada de dados de forma integrada, além de recursos e estruturas que garantem a preservação e a interoperabilidade dos dados.

\section{PROCEDIMENTOS METODOLÓGICOS}

Para a concepção e a realização do trabalho, primeiramente, foi realizada uma revisão na literatura biblioteconômica e preservacionista, utilizando o método hipotético-dedutivo,

[...] que consiste na construção de conjecturas, que devem ser submetidas a testes, os mais diversos possíveis, à crítica intersubjetiva, ao controle mútuo pela discussão crítica, a publicidade crítica e ao confronto com os fatos, para ver quais as hipóteses que sobrevivem como mais aptas na luta pela vida, resistindo, portanto, às tentativas de refutação e falseamento. (MARCONI; LAKATOS, 2000, p. 72).

O passo seguinte foi a elaboração de um estudo empírico principal através de questionário composto por 11 (onze) questões fechadas e 2 (duas) abertas, aplicado com entrevista junto a profissionais representantes de 12 (doze) bibliotecas técnico-científicas, integrantes da Rede de Bibliotecas da Fiocruz. Para além do levantamento principal detalhado anteriormente, também foram propostas algumas questões para a realização de levantamento complementar. Esse segundo levantamento de dados, foi realizado através de questionário auto aplicado composto por 4 (quatro) questões fechadas e 2 (duas) abertas, aplicados em 18 (dezoito) profissionais da informação oriundos de instituições sediadas no Estado do Rio de Janeiro, que participaram de fórum específico em preservação, organizado pela Biblioteca de História das Ciências e da Saúde coc/Fiocruz. 
Manoel Silva Barata; Gustavo Silva Saldanha

Preâmbulos à preservação digital na rede de bibliotecas da Fiocruz: estudo exploratório sobre a construção de ações institucionais voltadas à salvaguarda de suas coleções

Por fim, após o levantamento de dados completo, foi realizada uma reflexão comparada entre os elementos teóricos e aquelas questões técnicas e políticas no contexto das práticas e ações do bibliotecário atuante na preservação da informação técnico-científica digital no contexto das bibliotecas da Fiocruz e do fórum específico em preservação.

\section{$4 \quad$ RESULTADOS}

Para a análise definitiva do levantamento principal, realizou-se a aplicação de questionário com entrevista em 12 (doze) bibliotecários, representando a Rede de Bibliotecas da Fiocruz - o que corresponde a $25 \%$ do universo de bibliotecários em atuação na instituição, segundo dados fornecidos pela secretaria de gestão da Rede.

Do conjunto de análises efetivadas, destacamos para este artigo quatro, fruto das análises centrais da pesquisa.

Gráfico 1 - Crescimento acervo digital X papel

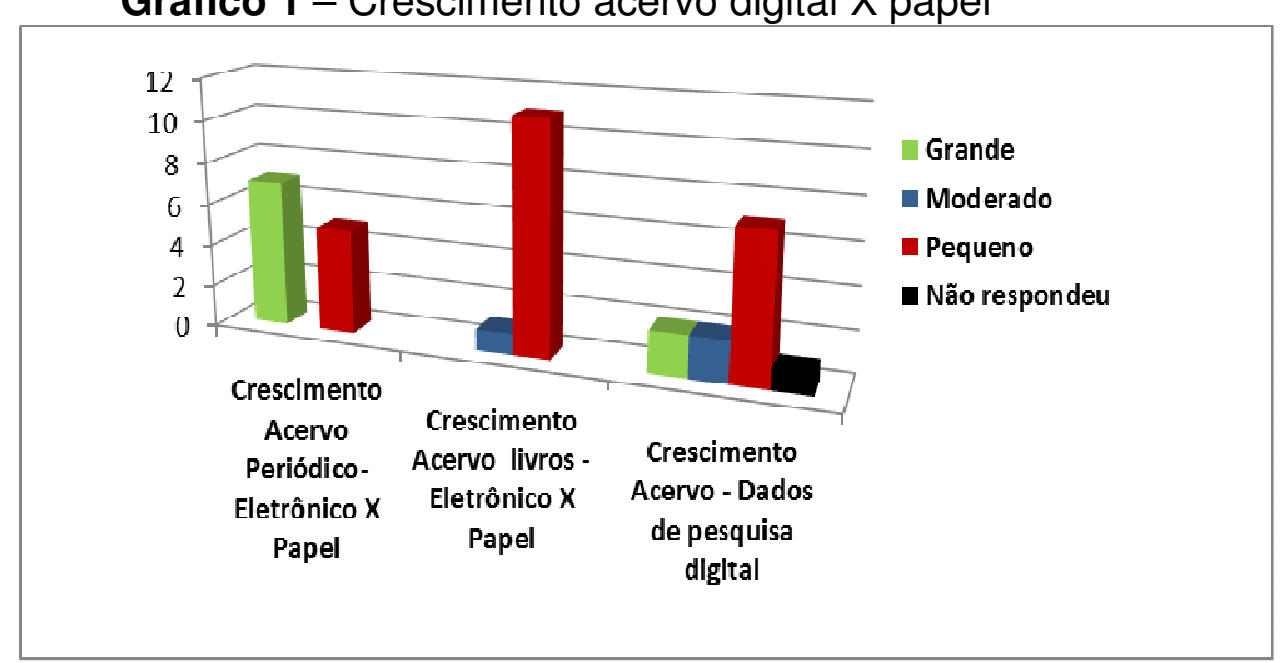

Fonte: Autoria própria.

A partir do Gráfico 1, pode-se notar que o crescimento de acervo de periódicos em formato eletrônico é maior do que aquele em formato em papel, impulsionado pela possibilidade do acesso facilitado ao 
usuário e pela indução do mercado editorial. Por outro lado, observa-se um elevado quantitativo de respostas, em que o crescimento do acervo de periódico eletrônico é considerado pequeno, devido a alguns fatores, a saber: a amostragem alcançou bibliotecas em que a aquisição de acervo digital ainda está em fase de planejamento; existem arestas que precisam ser aparadas nos contratos de assinaturas com as editoras relacionadas principalmente às formas de acesso, garantia do acesso perpétuo e preservação da memória técnico-científica para o futuro.

Atualmente, a insegurança com relação ao tempo de vida útil das assinaturas dos suportes digitais de informação é tão grande que mesmo com acesso ao digital, opta-se por se manter as assinaturas do impresso em papel para fins de resguardar a memória técnico-científica das diversas coleções historicamente preservadas pela instituição.

Percebe-se também que o crescimento de periódicos eletrônicos é maior que o crescimento de e-books, os quais, por sua vez, representam um pequeno crescimento na realidade da instituição analisada. No caso dos e-books, além da necessidade de contratos que garantam o acesso perpétuo ou outra forma alternativa de preservação da memória técnico-científica, ocorre que atualmente muitos títulos são publicados gratuitamente em portais de acesso aberto na Internet. Entretanto, aqueles que são comerciais e relevantes para algumas áreas do conhecimento, inclusive títulos internacionais, ainda carecem de uma maior adaptação conjunta na Rede de Bibliotecas, que está se empenhando e planejando para adquiri-los, debatendo ainda questões como: formas de acesso; controle de empréstimo (entre editora, bibliotecas e usuários); garantias de acesso perpétuo aos títulos adquiridos em contrato, dentre outras.

No caso dos e-books, também são identificadas questões culturais e naturais a determinadas áreas do conhecimento, pois em bibliotecas de algumas áreas, principalmente das ciências humanas e sociais, os usuários ainda preferem ler o impresso, possuir o físico, 
Manoel Silva Barata; Gustavo Silva Saldanha

Preâmbulos à preservação digital na rede de bibliotecas da Fiocruz: estudo exploratório sobre a construção de ações institucionais voltadas à salvaguarda de suas coleções

segurar e sentir o material original. Tendência esta que se confirma por relatos, de que mesmo com acesso ao digital, os usuários solicitam que os artigos sejam impressos. Além disso, ocorre que em outras áreas do conhecimento, como as editoras ainda não publicam e-books relevantes, muitas bibliotecas não realizam assinaturas destes, pela falta de demanda dos usuários e da comissão interdisciplinar de desenvolvimento de coleções da biblioteca.

Com relação aos dados de pesquisa, percebe-se que não existe uma cultura estabelecida pela gestão ou preservação dos dados, considerados muito "íntimos" dos pesquisadores. Assim, aqueles dados que fizeram parte do processo de construção do estudo do pesquisador, sejam as planilhas, rascunhos ou resumos, somente são armazenados, organizados e preservados pelas bibliotecas por solicitação direta dos pesquisadores. Como uma das missões tradicionais das bibliotecas é realizar a preservação das informações técnico-científicas publicadas formalmente, na ausência do volume e da demanda por dados digitais informais oriundos dos processos de pesquisa, ocorre ainda uma pequena preocupação com relação à seleção, organização e uso de ferramentas para a recuperação destes dados digitais ligados mais diretamente aos pesquisadores.

Gráfico 2 - Crescimento da demanda pelo acervo digital - Usuários, Instituição e profissionais capacitados em preservação digital

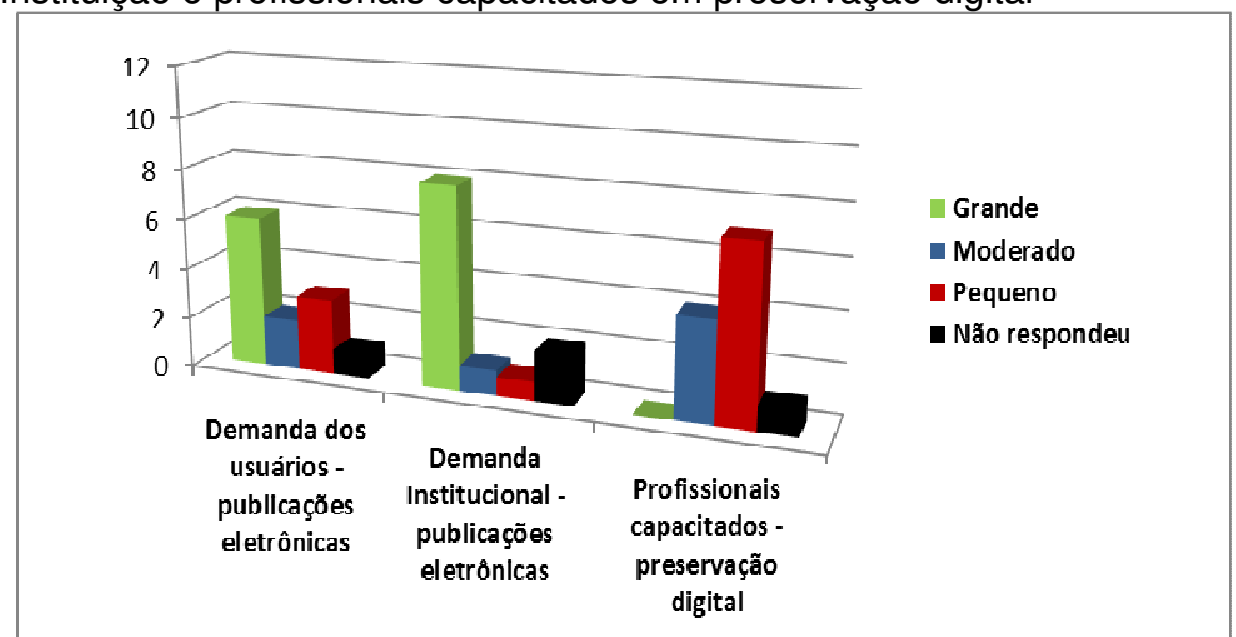

Fonte: Autoria própria. 
Tomando por base o Gráfico 2, observa-se que a demanda dos usuários por publicações eletrônicas é considerada grande para a maioria dos participantes na pesquisa. Esta demanda é sustentada pela facilidade e comodidade de acesso aos artigos de periódicos eletrônicos, pelo acesso ao texto completo de teses e dissertações solicitadas às bibliotecas via e-mail.

As bibliotecas também possuem algumas assinaturas controladas por IP, além das diversas fontes de acesso aberto que suprem parte desta demanda, como: o Portal de Periódicos da Capes, Biblioteca de Teses e Dissertações do IBICT, Portal Scielo, Repositórios Institucionais, e demais fontes de acesso aberto disponíveis na Internet. Basicamente, a variação da demanda dos usuários por publicações eletrônicas ou em papel reflete a relevância e a qualidade do conteúdo que as publicações eletrônicas possuem em determinadas áreas do conhecimento, assim como a cultura da área e dos usuários na preferência por determinado suporte de informação.

A demanda da instituição por publicações eletrônicas, de maneira global, é considerada grande. Como uma das iniciativas, neste sentido, temos a Política de Acesso Aberto da Fiocruz que estabeleceu o já mencionado ARCA como o repositório institucional oficial da Fiocruz.

No âmbito da formação continuada, grande parte das respostas sobre a capacitação do bibliotecário em preservação digital foi moderada, porém para a maioria dos participantes da pesquisa, a formação ainda deve ser aprimorada. Os bibliotecários estão procurando capacitação, pois sabem que, a falta de conhecimento sobre seleção, organização, indexação e curadoria sobre os documentos digitais, poderá prejudicar tanto a preservação, quanto a recuperação dos suportes digitais de memória técnico-científica. 
Manoel Silva Barata; Gustavo Silva Saldanha

Preâmbulos à preservação digital na rede de bibliotecas da Fiocruz: estudo exploratório sobre a construção de ações institucionais voltadas à salvaguarda de suas coleções

Gráfico 3 - Cooperação, padronização, racionalização das atividades preservação digital

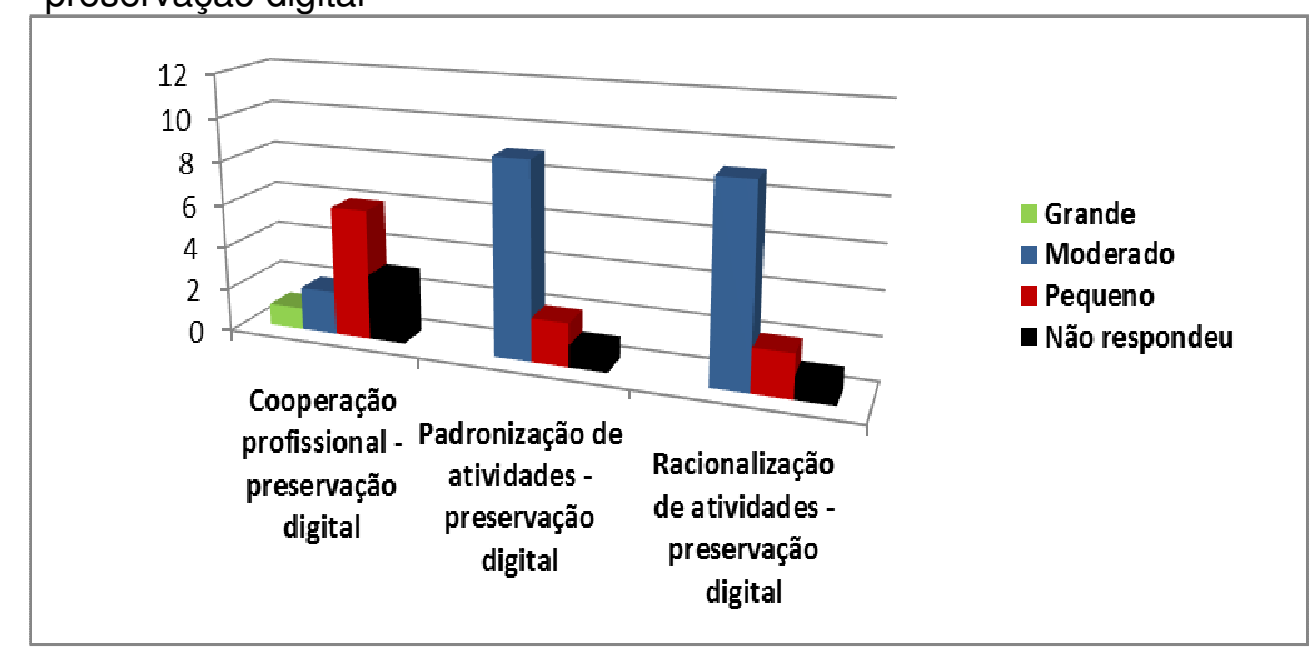

Fonte: Autoria própria.

O Gráfico 3 nos permite observar que a cooperação em preservação digital é considerada pequena pela maioria dos pesquisados, devido, principalmente, ao fato de que a maioria das bibliotecas da Rede Fiocruz, ainda estão iniciando seus processos em curadoria digital. No entanto, esta cooperação recentemente trilha um caminho ascendente, devido ao lançamento oficial do ARCA, em 2014, como Repositório Institucional da Fiocruz.

A cooperação em preservação digital na Rede de Bibliotecas deverá aumentar de forma exponencial, na medida em que os bibliotecários conseguirem ampliar a sua atuação com as coleções digitais, trazendo para o conjunto de processos das bibliotecas, maiores responsabilidades relacionadas à preservação da memória técnicocientífica digital. Além disso, os bibliotecários ainda possuem outros desafios para o aumento da cooperação profissional em preservação digital; dentre eles está a necessidade de um maior conhecimento e de uma participação mais efetiva no ciclo da informação técnico-científica digital.

No entanto, outros critérios importantes para serem pensados no momento de uma preservação digital eficaz foram considerados moderados, como a padronização e a racionalização das atividades, 
Manoel Silva Barata; Gustavo Silva Saldanha

Preâmbulos à preservação digital na rede de bibliotecas da Fiocruz: estudo exploratório sobre a construção de ações institucionais voltadas à salvaguarda de suas coleções

principalmente pelo fato de que atualmente e no decorrer desta pesquisa ocorreram e continuam surgindo novos projetos e iniciativas departamentais e institucionais voltadas para a melhoria destes processos.

Em sua maioria, os bibliotecários consideram tanto a padronização quanto a racionalização das atividades em preservação digital como moderadas, porque apesar dos bibliotecários demonstrarem um reconhecimento quanto ao seu papel para a preservação da memória técnico-científica e utilizarem em seu cotidiano algumas ferramentas da Biblioteconomia, compartilhadas pelas bibliotecas da Rede, estes percebem que ainda está por se desenvolver uma política integradora para a preservação digital no âmbito da Rede de Bibliotecas da Fiocruz.

Gráfico 4 - Relevância do envolvimento do bibliotecário em preservação digital

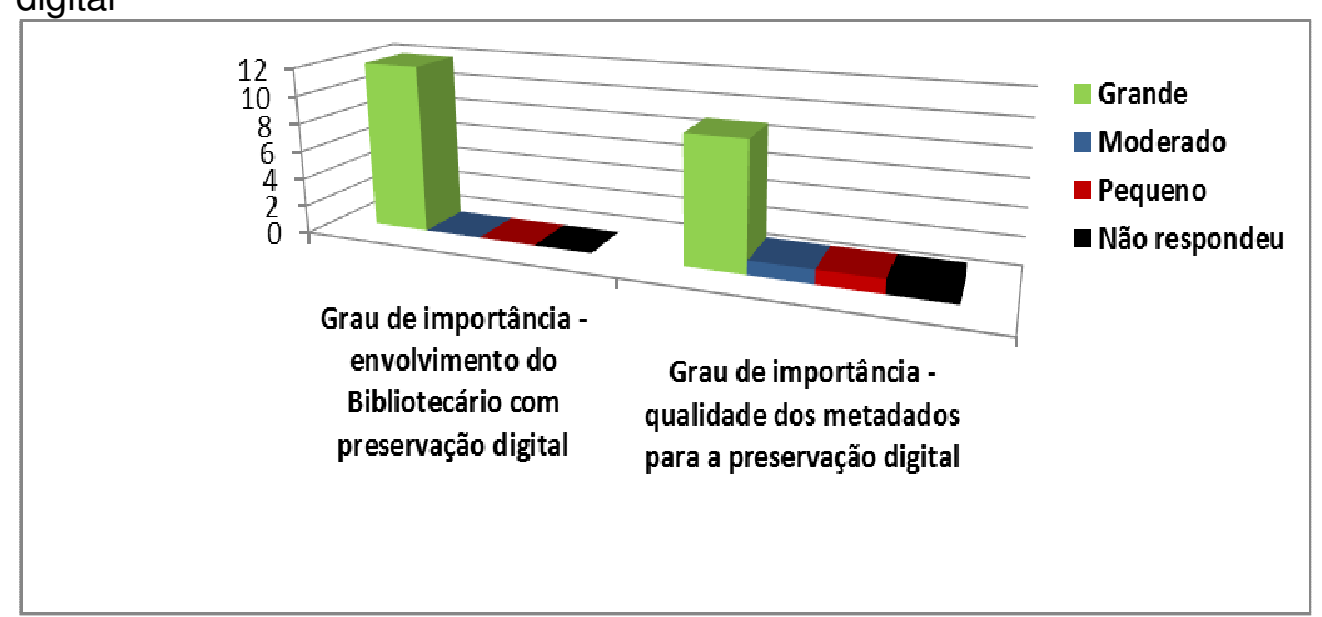

Fonte: Autoria própria.

No Gráfico 4, constata-se um elevado grau de consciência entre a maioria dos participantes sobre a importância do envolvimento do bibliotecário nas atividades de preservação digital, assim como na qualidade dos metadados para a preservação da memória técnicocientífica em suporte digital. Devemos ter claro, que o objeto digital, muitas vezes tem sido considerado como uma mercadoria, ou seja, possui valor enquanto está sendo consumido, porém sabemos que a 
informação técnico-científica possui um ciclo. Os bibliotecários sabem que com o livro impresso em papel vegetal, os direitos são do autor por determinado tempo, amanhã a informação passaria para uma biblioteca depositária e o bibliotecário seria o principal responsável pela preservação deste. Agora, como funcionaria hoje este ciclo para a preservação da memória técnico-científica em suporte digital?

$\mathrm{Na}$ avaliação complementar, realizada junto a dezoito participantes de fórum específico em preservação realizado na Fiocruz/COC, sobre o grau de importância do envolvimento do bibliotecário na elaboração de políticas e na realização de atividades em preservação digital, assim como com relação a importância da qualidade dos metadados e sobre a realização de backups constantes para o processo de preservação digital, obteve-se a reafirmação da grande importância dessas questões já anteriormente constatada no resultado do levantamento principal, seja para a efetivação de boas práticas para a gestão das coleções digitais realizadas pelo bibliotecário, seja para o aprimoramento dos processos de curadoria dos objetos digitais de informação a partir do ambiente das bibliotecas.

\section{CONSIDERAÇÕES FINAIS}

O bibliotecário, ao longo do tempo, constituiu-se no profissional responsável pela preservação da informação técnico-científica em suporte analógico, através dos livros, periódicos, jornais em papel, dentre outros. Com o avanço tecnológico e o surgimento do computador, da Internet, das bases de dados, dos documentos digitais, dentre outras tecnologias da informação, fez com que toda a equipe da biblioteca necessitasse de capacitação e atualização constante, pois os bibliotecários historicamente foram e continuam sendo os responsáveis diretos por suas coleções e, portanto, se o suporte informacional que compõe a coleção está em constante transformação, o bibliotecário tem a necessidade de encontrar meios de acompanhar esta mudança, 
envolver-se de forma efetiva para que consiga contribuir com modelos, programas e ações que venham proteger a memória técnico-científica digital para as futuras gerações.

Atualmente, os documentos técnico-científicos digitais possuem uma relevância muito grande, e, a partir deles algumas questões cresceram em complexidade, como a aquisição, a seleção, o processamento técnico, a criação de metadados ou descritores, a preservação e o acesso. Diante deste quadro atual em que 0 bibliotecário está imerso, saber como este profissional e teórico inserido diretamente no contexto de produção, circulação e uso destes documentos intervém técnica e politicamente nas ações institucionais de preservação da memória técnico-científica digital torna-se uma questão crucial e real.

Como resultado desta pesquisa, obteve-se a percepção de que atualmente existe um modelo em preservação digital institucional em construção, que congrega diversas iniciativas, além de um grande esforço na superação de desafios que envolvem a preservação da memória técnico-científica. Através de documentos analisados verificouse que já existem políticas e programas em desenvolvimento, além de muitas ações em que o bibliotecário pode se envolver e contribuir.

A preservação da memória técnico-científica digital, diferentemente da memória técnico-científica analógica, caracteriza-se por ser mais complexa quando tratamos da noção de durabilidade e da noção de confiabilidade, e demanda uma constante reavaliação interdisciplinar. Desta forma, entende-se que atualmente este tema pode ser investigado por diversas disciplinas acadêmicas, dentre elas está a Biblioteconomia, ou seja, para questões acadêmicas as diversas disciplinas de forma isolada podem realizar pesquisas sobre pontos de vista diferenciados, porém quando a preservação da memória técnicocientífica digital passa para o campo empírico, ou para o campo da prática em empresas, universidades, dentre outras, esta necessita da 
atuação compartilhada entre diversas áreas do conhecimento para que seus resultados sejam eficazes e positivos.

\section{REFERÊNCIAS}

BASE Arch. 2014. Disponível em: <http://www.coc.fiocruz.br/index.php>. Acesso em: 29 mar. 2014.

DARNTON, Robert. A questão dos livros: passado, presente e futuro. São Paulo: Companhia das Letras, 2010.

DODEBEI, Vera. Digital virtual: o patrimônio no século XXI. In: DODEBEI, Vera; ABREU, Regina (Org.). E o patrimônio ?. Rio de Janeiro: Contra Capa, 2008.

DOMINGUES, Heloisa Maria Bertol. Carlos Chagas Filho: um articulador da história das ciências do Brasil. História, Ciências, Saúde -

Manguinhos, Rio de Janeiro, v.19, n.2, p. 637-651, abr./jun. 2012. Disponível em: <http://www.scielo.br/pdf/hcsm/v19n2/ahop0212>. Acesso em: 04 out. 2014.

FERREIRA, Miguel. Introdução à preservação digital: conceitos estratégias e actuais consensos. Guimarães: Escola de Engenharia da Universidade do Minho, 2006. Disponível em:

<http://repositorium.sdum.uminho.pt/bitstream/1822/5820/1/livro.pdf>. Acesso em: 31 maio 2014.

FONSECA, Maria Cecília Londres. O patrimônio em processo: trajetória da política federal de preservação no Brasil. Rio de Janeiro: UFRJ, 2009.

FREYRE, Éder de Almeida (Org.). Arca - Repositório Institucional da Fiocruz: manual de tratamento de dado. Rio de Janeiro: ICICT, 2013.

LE GOFF, Jacques. História e memória. Campinas: UNICAMP, 1996.

MARCONI, Marina de Andrade; LAKATOS, Eva Maria. Metodologia científica. São Paulo: Atlas, 2000.

NABUCO, Joaquim. Em defesa do livro: a conservação das nossas bibliotecas e arquivos. 2. ed. Rio de Janeiro: Antunes \& Cia, 1959. 
PINHEIRO, Marcos José de A.; SANTOS, Paulo R. E; COELHO, Carla M. T. Complexo de preservação e difusão de acervos culturais e científicos da saúde. In: CONFERENCE ON TECHNOLOGY, CULTURE AND MEMORY - CTCM, Strategies for preservations and Information access, 13., 2011, Recife. Anais eletrônicos... Recife: Instituto Ricardo Brennand, 2011. Disponível em:

$<$ http://www.liber.ufpe.br/ctcm/anais/anais_ctcm/34_saude_acervos.pdf> . Acesso em: 08 out. 2014.

RÉNDON ROJAS, Miguel Angel. Bases teóricas y filosóficas de la Bibliotecología. México D.F: UNAM, Centro Universitário de Investigaciones Bibliotecológicas, 2005. Disponível em: $<$ http://libros. metabiblioteca.org/bitstream/001/402/8/970-32-26795.pdf>. Acesso em: 31 maio 2014.

SILVA, Adagilson Batista Bispo da. Estratégias de preservação digital em centros de pesquisas da Fiocruz. 2010. 89 f. Dissertação (Mestrado Profissional em Saúde Pública) - Centro de Pesquisas Aggeu Magalhães, Fundação Oswaldo Cruz, Recife, 2010. Disponível em: <http://www.cpqam.fiocruz.br/bibpdf/2010silva-abb.pdf>. Acesso em: 31 maio 2014.

UNESCO. Preserving our documentary heritage. 2005. Disponível em: <http://www.unesco.org>. Acesso em: 31 maio 2014.

\section{Title}

Introduction to the digital preservation in the Fiocruz Library Network: an exploratory study on the construction of institutional actions

\section{Abstract}

Introduction: This study aims to present technical and theoretical contributions to the field of preservation in library science, especially with regard to scientific information stored in digital media.

Objective: To understand the Librarian action in the preservation of contemporary digital technical and scientific memory under Library Science point of view, from analysis of Fiocruz's Library Network.

Methodology: A theoretical analysis: through literature review of philosophical reason to "preserve" and "theoretical" role of preservation in the context of the Library. An empirical analysis: through the use of questionnaires in interviews with active librarians Fiocruz's Library Network, as well as secondary survey from questionnaires to participants librarians in specific forum in preservation in the institution.

Results: Within the context of preservation's practices in the Fiocruz have allowed us to get some results coming from theoretical and empirical reflection 
Manoel Silva Barata; Gustavo Silva Saldanha

Preâmbulos à preservação digital na rede de bibliotecas da Fiocruz: estudo

exploratório sobre a construção de ações institucionais voltadas à salvaguarda de suas coleções

on the librarian's action for the benefit of digital preservation under the librarianship point of view in the context of Fiocruz's Library Network.

Conclusions: The preservation of digital technical and scientific memory, unlike analog technical and scientific memory, characterized by being more complex when dealing with the notion of durability and the notion of reliability, and demand a constant interdisciplinary reassessment. It is now understood that this issue can be investigated for various academic disciplines, among them is the Library Science.

Keywords: Digital Preservation. Librarian. Library Science Theory and Research. Fiocruz.

\section{Titulo}

Introducción a la preservación digital en la Red de Bibliotecas de Fiocruz: un estudio exploratorio acerca de la construcción de acciones institucionales

\section{Resumen}

Introducción: Este artículo pretende presentar una contribución teórica y empírica a los estudios de preservación en Biblioteconomía, en particular con respecto a la información técnica y científica almacenada en los medios digitales.

Objetivo: Comprender la acción del Bibliotecario en la preservación de la memoria técnica y científica digital contemporánea bajo punto de vista biblioteconômico, desde el análisis de la Red de Bibliotecas del Fiocruz.

Metodología: La metodología incluye: un análisis teórico a través de revisión de la literatura acerca de la preservación en Biblioteconomía; un análisis empírico mediante el uso de cuestionarios con entrevistas a los bibliotecarios activos en Red de Bibliotecas de Fiocruz, así como evaluación secundaria, a partir de cuestionarios aplicados de a los bibliotecarios que participan en un foro específico de preservación en la institución.

Resultados: El estudio arrojó resultados derivados de la reflexión teórica y empírica sobre la acción bibliotecaria para el beneficio de la preservación digital bajo el punto de vista biblioteconômico, en el contexto de la Red de Bibliotecas de Fiocruz.

Conclusión: La preservación de la memoria técnica y científica digital, a diferencia de la memoria técnica y científica analógica, caracterizada por ser más compleja cuando se trata de la noción de la durabilidad y la noción de fiabilidad, y exigir una nueva evaluación interdisciplinaria constante. Ahora se entiende que este problema puede ser investigado por diversas disciplinas académicas, entre ellos se encuentra la Bibliotecología.

Palabras clave: Preservación digital. Bibliotecario. Teoría de la Bibliotecología. Fiocruz.

Recebido em: 10.10 .2015

Aceito em: 20.12.2015 